

\title{
LAS ECONOMÍAS \\ COLABORATIVAS EN \\ TURISMO, ¿UNA \\ RESPUESTA DE \\ DESARROLLO \\ ECONÓMICO \\ SOSTENIBLE? CASO \\ ALOJAMIENTOS CIUDAD \\ DE MEDELLÍN
}

\author{
Luisa Larrea David \\ luisa.larrea@colmayor.edu.co \\ Colegio Mayor de Antioquia
}

Resumen

El fenómeno de las economías colaborativas es un tema que ha causado controversia en todo el mundo; la economía colaborativa se ha popularizado en sectores relacionados con el turismo como el transporte y el alojamiento. Este estudio empresarial cuyo objetivo fue el de analizar la contribución de las economías colaborativas en alojamiento al desarrollo económico sostenible de los territorios.

Para los fines de esta investigación, se diseñó un modelo metodológico mixto, apoyado en instrumentos cualitativos como la entrevista, observación y revisión bibliográfica, e instrumentos como la encuesta a empresarios turísticos tradicionales. La aplicación de la metodología permitió conocer los cambios que ha experimentado el alojamiento tradicional en la zona de Laureles-Estadio de la comuna 11 en Medellín; estos cambios están principalmente relacionados con el acceso al mercado, así como con una de las principales preocupaciones de los empresarios de alojamiento tradicional, la regulación empresarial turística del país que hasta ahora no se tiene en cuenta para las empresas colaborativas. Si se quiere promover un ambiente donde ambos tipos de alojamiento puedan relacionarse en el mercado mediante una convivencia empresarial, el primer paso debe ser que el sector público genere una regulación que tenga en cuenta las necesidades y particularidades de ambos, así como la igualdad en las condiciones que se establecen para la operación del servicio de alojamiento.

\footnotetext{
Palabras clave

Economía colaborativa, alojamientos turísticos, economía naranja, alojamientos alternativos.
} 


\section{Introducción}

El turismo es una de las economías más prósperas y una de las opciones más viables y sostenibles para muchos países en desarrollo, al considerarse como una de las principales fuentes de divisas a nivel mundial (Organización Mundial del Turismo, 2017). Este sector, cada vez más, es reconocido como un factor clave para el desarrollo socioeconómico, por su gran aporte a la construcción de paz, y por su contribución a la prosperidad y al bienestar de las naciones; es por esto que durante las seis últimas décadas la actividad turística ha experimentado una continua expansión y diversificación, lo que se ha visto reflejado en la generación de empleos, el fortalecimiento del tejido empresarial, apoyo a nuevos emprendimientos, al mejoramiento de la calidad de vida y en general la puesta en valor de la riqueza natural y cultural de los territorios (Vergara, 2013).

En Colombia, el 23 de mayo de 2017 se publicó la ley 1834, conocida como la "Ley Naranja", por medio de la cual se fomenta la economía creativa en el país. Entendida esta como aquella que promueve las industrias donde se genera valor en razón de sus bienes y servicios fundamentados en la propiedad intelectual, (Colombia, 2017). Esta ley además busca fomentar el emprendimiento el sector de los servicios y contempla al turismo como un importante eje de desarrollo económico para el país. De la misma manera y desde el año 2012, el Ministerio de Comercio, Industria y Turismo, publica los lineamientos de política para el desarrollo de turismo comunitario en Colombia y desde entonces, el turismo se contempla como una 
alternativa generadora de recursos e ingresos para las comunidades locales de los destinos donde se desarrolla la actividad.

Como resultado de las iniciativas del gobierno nacional, se estimula en las personas naturales la creación de negocio, sin embargo, estos nuevos emprendedores ignoran o dejan de lado la normatividad y formalismos previamente establecidos también por ley (Ley 1558 de 2012) que buscan el desarrollo sostenible, competitivo y de calidad de las industrias en el país. Esta situación pone en un mismo lugar o destino turístico que a su vez constituye un mercado: empresas legalmente constituidas y formalizadas con personas naturales que tienen iniciativas de negocio de tipo colaborativo e informal lo cual genera choques entre ambos modelos de negocio y a su vez inestabilidad en el mercado de servicios de alojamiento turístico.

Las practicas colaborativas a nivel mundial han cobrado gran relevancia a tal medida que incluso se puede hablar de que los emprendimientos colaborativos se han convertido en competidores de empresarios de productos y servicios con oferta de similares o sustitutos.

Gracias al auge de las comunicaciones y el uso de tecnologías de información cada vez es más fácil acceder de manera colaborativa a satisfacer nuestras necesidades del día a día. En el contexto del turismo la economía colaborativa también ha cobrado protagonismo trayendo al plano del mercado diversas alternativas de alojamiento que entran a disputarse cuota de viajeros con los tradicionales hoteles.

Es importante conocer cómo estas nuevas tendencias colaborativas plantean retos y cambios en los modelos de negocio tradicionales de las 
empresas de alojamiento de Medellín, una de las ciudades más turísticas de Colombia.

El presente es un estudio empresarial busca indagar sobre las posibilidades reales de desarrollo económico en los territorios a partir de la implementación de economías colaborativas propiamente en turismo, estudia los cambios que ha tenido el modelo de negocio en la industria del alojamiento tradicional y modelos de negocio alternativos donde prima el favorecer a las comunidades locales de los territorios.

A través de un estudio de carácter mixto que emplea técnicas de recolección de información como observación, encuesta y entrevista, se busca analizar que los emprendimientos de tipo colaborativo en alojamiento, sean actividades verdaderamente sostenibles, que generen riqueza para sus operadores, satisfacción para sus usuarios y diversos beneficios económicos, sociales y ambientales para las poblaciones donde se desarrollan.

A partir de los siguientes objetivos específicos:

- Reconocer el modelo de negocio tradicional de alojamiento en la ciudad de Medellín.

- Identificar acciones de economía colaborativa en alojamiento (Airbnb) en la ciudad de Medellín.

- Establecer los puntos de encuentro y diferencias entre los dos modelos, economía tradicional y economía colaborativa para la industria de alojamiento en Medellín.

- Generar propuestas de integración entre los dos modelos de economía, tradicional y colaborativa para la industria del alojamiento, que den respuesta a los cambios del entorno.

\section{Marco teórico}


Desde los aspectos legales del turismo en el país, la ley general que regula la actividad es la 1558 de 2012, la legalidad de las empresas de turismo en Colombia, conocidas como prestadores de servicios turísticos, está limitada y reglamentada por la inscripción de estas empresas ante el Registro Nacional de Turismo (RNT) y su actualización durante el primer trimestre de cada año a cargo de las cámaras de comercio locales, así como el pago de los aportes a la contribución parafiscal que hacen las empresas y que financian el desarrollo de proyectos relacionados con competitividad y mercadeo a nivel nacional a través del Fondo Nacional de Turismo del país (FONTUR).

En el caso de los prestadores de servicios de alojamiento, de acuerdo con la ley 1558 de 2012, se entiende por establecimiento hotelero o de hospedaje, el conjunto de bienes destinados por la persona natural o jurídica a prestar el servicio de alojamiento no permanente inferior a 30 días con o sin alimentación, servicios básicos y/o complementarios, mediante contrato de hospedaje, el cual es un contrato de arrendamiento, de carácter comercial en el cual una empresa dedicada a ésta actividad celebra con el propósito principal de prestar alojamiento a otra persona llamada huésped, mediante el pago del precio respectivo día a día.

A pesar de que se evidencia que los aspectos legales del turismo en Colombia y la normatividad que rige a las empresas prestadoras de servicios turísticos en el país han evolucionado a través de los cambios en la ley, desde el análisis de la misma se puede decir que en general, la norma ha estado años atrás alejada del contexto real de la actividad y de 
las necesidades tanto de la oferta (empresarios del turismo) como de la demanda (turistas).

Los orígenes de la economía colaborativa y del sistema de trueque se remontan a los años 70' donde en el norte del continente americano, propiamente en Canadá se promovieron experiencias colaborativas y comunitarias principalmente por jóvenes sin recursos económicos. A la par en Alemania y Estados Unidos se pusieron en marcha proyectos de intercambio basados en la colaboración de sujetos y bienes. (Valor, 2014)

En los años 80' el modelo de cooperación basado en la colaboración se expande a Australia, Nueva Zelanda y Reino Unido donde el trueque se presenta en contextos sociales y financieros. Durante los años 90 este estilo poco convencional de economía basada en el intercambio y paralelo a las entidades financieras tradicionales llega a Holanda, Francia y España donde empresas particulares acogieron el sistema de cooperativismo, intercambiaron bienes y servicios e incluso para regular los intercambios se crean monedas alternas a las de la economía formal y bancaria. En américa latina este modelo llega primeramente a Argentina y es conocido como el "cambalache", los modelos colaborativos llegan para fortalecer las relaciones sociales y los modos de vida de las clases media y baja donde no solo se intercambian bienes si no también servicios y que posteriormente con la llegada de tecnologías de la información estos intercambios se expanden a diferentes entornos geográficos y modalidades hasta llegar a proponer nuevas formas de 
viajar y una relación persona a persona que se encuentra por fuera del sistema económico tradicional. Valor, C. (2014).

De acuerdo con J. Díaz Armas, Gutiérrez Taño \& J. García Rodríguez. (2015) no solo la oferta se comporta de un modo poco convencional en la economía colaborativa, sino que también la demanda lo hace y la percepción del consumidor frente al fenómeno también cambia hasta el punto de ser cada vez más aceptado y utilizado.

Por su parte, A. Guillén Navarro \& T. Iñiguez Berrozpe. (2016) describen el perfil del turista o viajero consumidor de los servicios de viviendas turísticas en España y que podría eventualmente serlo en contextos latinoamericanos como Medellín. Los autores hacen además una descripción de lo que sería un modelo de turismo colaborativo "puro" (sin transacción económica) y un modelo "hibrido" como el que platean plataformas de intermediación en alojamiento como Airbnb, comisionable y con ánimo de lucro.

La economía colaborativa ocasiona impactos y demanda generación de estrategias de transformación empresarial principalmente en las Pequeñas y Medianas Empresas (PYMES), Gómez J \& Martínez R (2018) abordan las PYMES como un elemento clave a la hora de hablar de economía colaborativa, puesto que es en esta categoría en donde se encuentran los emprendimientos de tipo colaborativo que han surgido durante los últimos años en la ciudad y el país, a través de estrategias colaborativas en los territorios se puede llegar a dar una transformación empresarial enfocada en las pequeñas y medianas empresas, los autores evidencian el cambio en la composición empresarial que se viene 
presentando en el país y donde los negocios tradicionales se ven cada vez más en extinción.

Para definir la economía creativa nos remitimos a varios autores que desde los orígenes del concepto en 1999, han estudiado y escrito sobre el tema. De acuerdo Duisenberg, la economía creativa es de enfoque holístico y multidisciplinario, manejando la interfaz entre la economía, la cultura y la tecnología, centrada en la predominancia de los productos y servicios con contenido creativo, valor cultural y objetivos de mercado, resultante de un gradual cambio de paradigma. (Ana Carla Fonseca Reis Organización, 2008)

En mayo de 2017, el Congreso de la Republica aprueba la ley 1834, conocida como la "Ley Naranja", promovida por el entonces congresista y actual presidente de la república de Colombia, Iván Duque Márquez, la ley tiene por objeto: proponer, desarrollar, fomentar, incentivar y proteger las industrias creativas; entendidas como aquellas industrias que generan valor debido a sus bienes y servicios, los cuales se fundamentan en la propiedad intelectual.

\footnotetext{
"El Gobierno nacional tomará las medidas necesarias para que las industrias creativas nacionales sean exaltadas, promocionadas, incentivadas, protegidas y reconocidas. Para ello coordinará articuladamente sus esfuerzos, con miras a visibilizar este sector de la economía promoviendo su crecimiento e identificándolo como un sector generador de empleo de calidad, motor de desarrollo, y que fomenta el tejido social y humano, así como la identidad y equidad". (Colombia C. d., 2017)
}

La economía creativa de acuerdo con los expertos presenta unas características particulares que la distinguen y separan de la economía tradicional: 
Valor agregado de la intangibilidad: El carácter intangible de la creatividad genera valor agregado al incorporar características culturales, abarcando patrimonio y fiestas típicas, hasta el audiovisual, se crean sinergias entre el estilo de vida y el entorno en el que emerge.

Desde la cadena sectorial hasta las redes de valor: La economía creativa se estructura en forma de red. La producción y el consumo son impulsados por las nuevas tecnologías, en lugar de seguir el tradicional modelo, se despliegan en una gama de posibilidades de muchos productores para muchos consumidores.

Nuevos modelos de consumo: la economía creativa se basa en una ampliación de los modelos de consumo existentes, a partir de la tecnología, brinda al consumidor el protagonismo de sus decisiones de consumo e identidad cultural que representada en los bienes y servicios un carácter único.

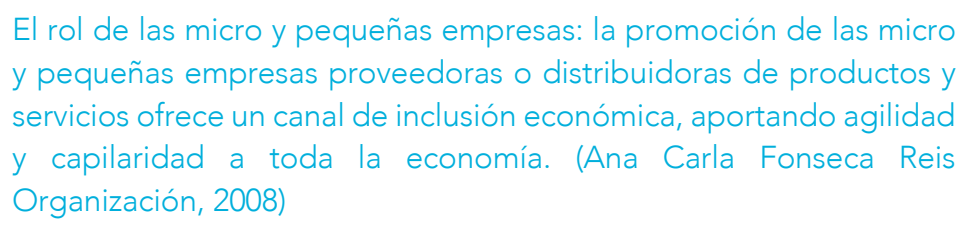

La economía creativa de alguna u otra forma se relaciona con lo que comúnmente se conoce como la economía naranja pues esta le apunta a promover la innovación, la creatividad y tecnologías digitales, para que con menos recursos se pueda crear y generar soluciones sostenibles que aporten al desarrollo y a la economía para que estas impacten a la sociedad y los consumidores de productos y servicios acorde a sus necesidades, requerimientos y capacidades. Uno de los aspectos o categorías de la economía naranja es el trabajo colaborativo en 
plataformas de negocios y empleos para apoyar la gestión y los servicios de personal creativo independiente como estrategia para apoyar su trabajo y procesos productivos (Portafolio, 2018), que esto es justamente en lo que está basado la economía colaborativa y así están funcionando actualmente las aplicaciones APPS que se basan en esta modalidad.

En cuanto a estilos de vida colaborativos en turismo, se refiere a los hábitos de los viajeros en los cuales eventualmente se incluyen actividades y prácticas relacionadas con la economía colaborativa que buscan dinamizar la economía del territorio desde su población local y emprendimientos. Díaz Armas (2014)

Para que exista el turismo colaborativo en alojamiento, se requiere que tanto anfitrión como viajero adopten dicho estilo de vida y estén dispuestos a compartir e intercambiar recursos tangibles e intangibles en el destino turístico, y generar una relación que supera lo comercial ya que vincula filosofías de vida.

\section{Metodología}

Tipo de investigación: descriptiva bajo un método no experimental, en la cual el investigador no tiene control sobre las variables por tratarse de fenómenos y procesos sociales, es de tipo descriptiva, ya que el objeto de la investigación es enunciar las características del fenómeno.

La investigación sigue una estrategia explicativa ya que el problema de investigación indaga por la razón de situaciones o acontecimientos 
relacionados a los cambios en los modelos de negocio tradicional de alojamiento por la llegada de economías colaborativas y la relación que tienen estas cuando se habla de desarrollo económico sostenible.

Para este estudio, se diseñó un modelo investigativo de carácter mixto con variables que se pretenden analizar miden tanto cualidades o características del fenómeno turístico, así como también cantidades, dirigido a comprender y profundizar sobre los modelos tradicionales de negocio frente a los modelos de economía colaborativa.

Variables: las variables a abordar en la presente investigación en se muestran en la tabla $N^{0} 1$ diferenciadas para los alojamientos tradicionales: hoteles y hostales, y para los nuevos modos de alojamiento de acuerdo con economías colaborativas.

Tabla Nº 1 Variables a investigar

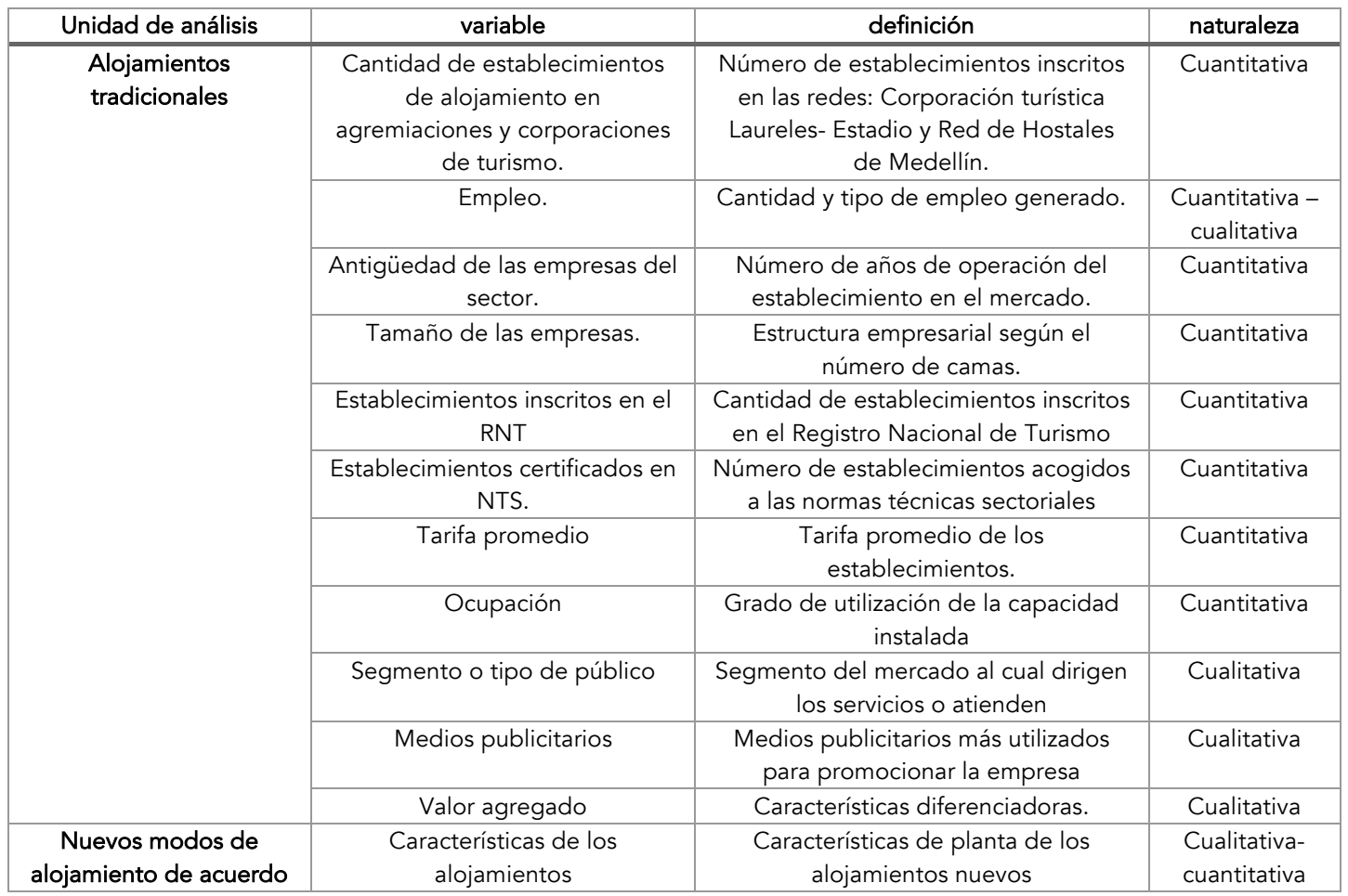




\begin{tabular}{|c|c|c|c|}
\hline \multirow[t]{4}{*}{$\begin{array}{l}\text { a economías } \\
\text { colaborativas }\end{array}$} & Tarifa promedio & $\begin{array}{c}\text { Valor promedio de la noche por } \\
\text { persona en los alojamientos } \\
\text { colaborativos }\end{array}$ & Cuantitativa \\
\hline & Medios publicitarios & $\begin{array}{l}\text { medios publicitarios más utilizados } \\
\text { para promocionar el alojamiento }\end{array}$ & Cualitativa \\
\hline & $\begin{array}{c}\text { Establecimientos inscritos en el } \\
\text { RNT }\end{array}$ & $\begin{array}{c}\text { Cantidad de establecimientos inscritos } \\
\text { en el RNT }\end{array}$ & Cuantitativa \\
\hline & Valor agregado & $\begin{array}{c}\text { Características diferenciadoras de los } \\
\text { alojamientos turísticos frente a los } \\
\text { aojamientos tradicionales. }\end{array}$ & Cualitativa \\
\hline
\end{tabular}

Población: se plantea un estudio de casos empresariales dirigido a los hoteles y alojamientos pertenecientes a la Corporación de hoteles del sector Laureles-Estadio y Red de Hostels Medellín, que agremia a los establecimientos de alojamiento de la comuna 11 (laureles) de la ciudad de Medellín.

Además, se realizan entrevistas a expertos temáticos, directores y encargados de los gremios de alojamientos y autoridades en turismo de la ciudad de Medellín.

Instrumentos de Medición y Técnicas: se identifica la revisión bibliográfica de fuentes secundarias; que consiste en el análisis de contenido de documentos y normatividad con el apoyo de fichas bibliográficas.

Aplicación de encuestas a los encargados de los establecimientos de alojamiento tradicionales y realización de entrevistas a las directoras de la Corporación de Turismo Laureles-Estadio y Red de Hostels Medellín. La entrevista será semiestructurada, es decir que existe relativo grado de flexibilidad tanto en el formato como en el orden y los términos de realización de esta para las diferentes personas a quienes está dirigida.

Instrumentos: Ficha bibliográfica, cuestionario, guía de entrevista. 
Fuentes: Se utilizan fuentes primarias y secundarias: normatividad local, nacional e internacional, archivo histórico, artículos de revistas científicas, estudios y recomendaciones de entes idóneos, entrevista a las directoras de las corporaciones alojamiento de la ciudad y encuesta a los empresarios de los establecimientos pertenecientes a los gremios.

\section{Resultados}

Si se trata de establecer si el auge de economías colaborativas en el sector turístico específicamente relacionadas con alojamiento, podrían ser consideradas como una propuesta desarrollo económico sostenible en los destinos y territorios, además alineada con lo planteado en los objetivos del milenio, se debe empezar por analizar entonces el comportamiento de los empresarios tradicionales en la industria del alojamiento y los cambios que estos han sufrido a raíz de la llegada de esta nueva alternativa de emprendimientos colaborativos asociados al sector.

La presencia de los emprendimientos colaborativos en turismo y propiamente en alojamiento en una zona o espacio geográfico donde tradicionalmente han estado presentes empresarios formalizados y de muchos años, contribuye a que de alguna manera el mercado se desestabilice en cuanto encontramos en un mismo espacio diferentes tipos de oferta en este caso de alojamiento para un solo tipo de turista, que ahora deberá tomar la decisión de si se hospeda en un hotel u alojamiento tradicional o hace uso de plataformas colaborativas como 
Airbnb para encontrar habitaciones en casas 0 apartamentos residenciales donde pernoctar.

En este sentido son los alojamientos tradicionales y formalmente constituidos quienes deben exponer sus perspectivas de desarrollo económico en vista de la presencia de alojamientos colaborativos en el mercado. Esto permitirá saber si las economías colaborativas contribuyen de una manera eficiente a la generación del desarrollo económico en un territorio o si por el contrario se convierten en una alternativa informal y poco regulada cuyos resultados e impactos en el desarrollo económico de un territorio no son medibles.

La base empresarial de alojamientos tradicionales se encuentra formalizada de acuerdo con los requerimientos de la ley general de turismo del país y genera empleo formalmente, es por esto por lo que su contribución al desarrollo económico de un territorio es evidente, por otra parte, se encuentran los emprendimientos e iniciativas de tipo colaborativo las cuales se convierten en un sustituto de los servicios tradicionales y de la base empresarial formalizada.

Los ingresos económicos y divisas generadas por los alojamientos colaborativos no están representados ni incluidos dentro de las estadísticas o los datos de crecimiento económico del territorio por lo tanto la medición del desarrollo y mejora en las condiciones del lugar a causa de este tipo de iniciativas queda incierta.

Es importante identificar cómo la presencia de alojamientos colaborativos en la zona ha cambiado las condiciones de mercado para el empresario tradicional y cómo este visualiza a esos nuevos empresarios, así como hay que proponer acciones de integración de 
mercado donde se permita que en un mismo territorio convivan estos dos tipos de estructuras.

Analizando la zona de estudio (Laureles-Estadio) se evidencia una caída en los porcentajes de ocupación hotelera a partir del año 2016, los históricos demuestran que esta variable presenta un comportamiento poco constante tal y como se muestra en la imagen $N^{\circ} 1$, lo que no permite a los gestores de los gremios y empresarios realizar proyecciones acertadas, la totalidad de los empresarios encuestados le atribuyen la caída de la ocupación a la popularización de las plataformas colaborativas relacionadas con alojamiento que presentan oferta en la zona.

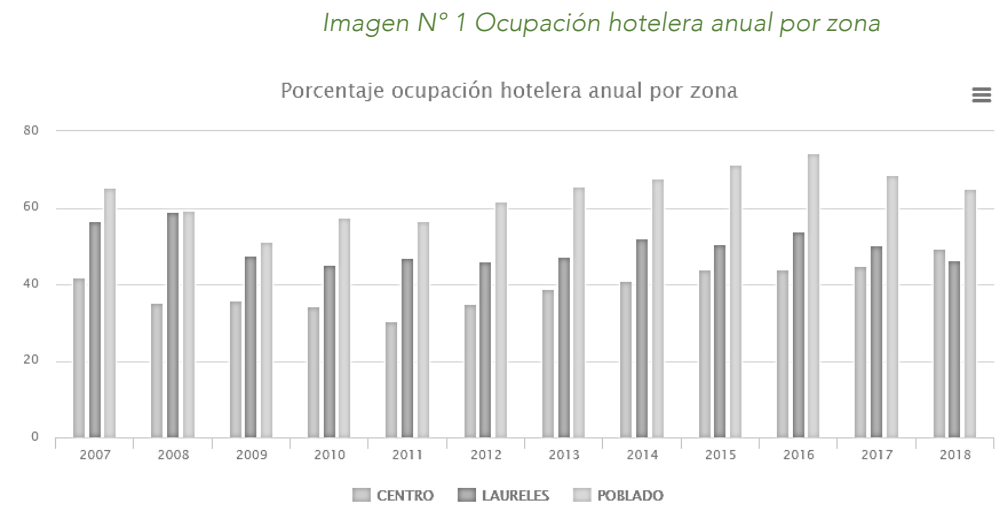

Fuente: Sistema de indicadores turísticos Medellín-Antioquia SITUR

Se identifican las acciones de economía colaborativa en alojamientos ofrecidos a través de Airbnb en la ciudad de Medellín por medio de rastreo web y en plataformas de intermediación donde se permite evidenciar la cantidad de alojamientos ofrecidos en la ciudad y sus características como infraestructura, servicios ofrecidos y tarifas. Para el análisis de datos de Medellín la información se filtra por el registro en Airbnb principalmente y se presenta en las siguientes imágenes: 


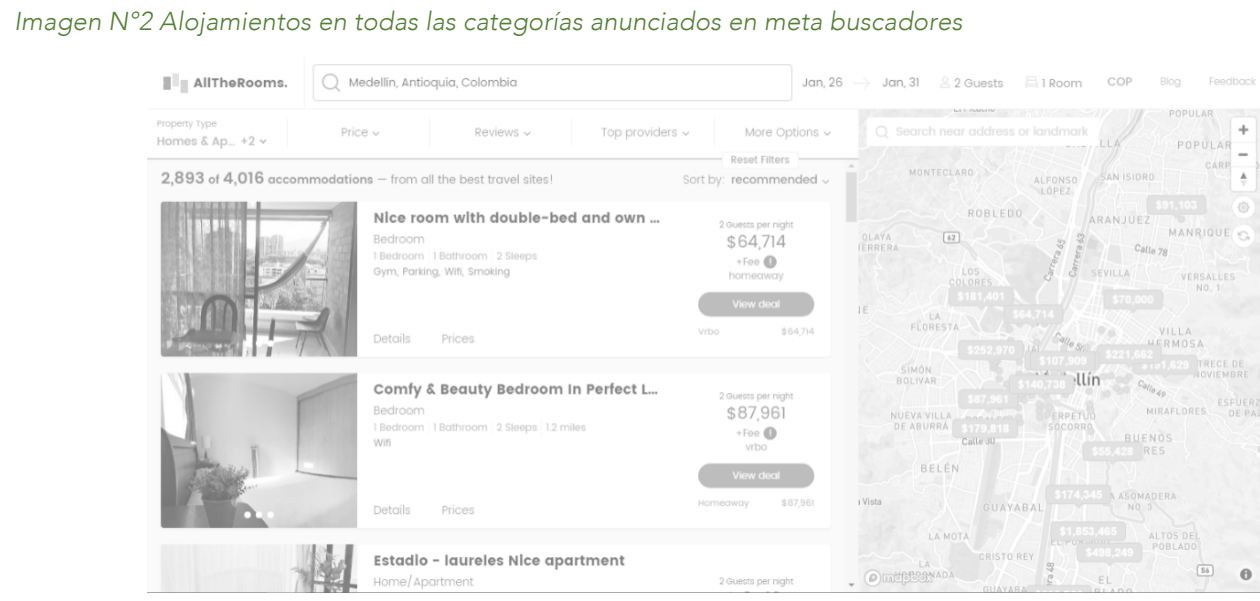

Fuente: Data Analytics All The Rooms

En total en la ciudad se encuentran registrados 4.016 sitios de alojamiento tanto formales como informales. Si se aplica un filtro para observar solo casas, apartamentos, habitaciones (iniciativas colaborativas) se encuentra una oferta de 2.893 alojamientos en Medellín anunciados en los principales metabuscadores fuente de búsquedas a nivel mundial.

En la imagen $\mathrm{N}^{\circ} 3$ se presenta el crecimiento anual que ha tenido la oferta de alojamientos colaborativos anunciados en la plataforma Airbnb en la ciudad de Medellín del año 2010 al 2019. 


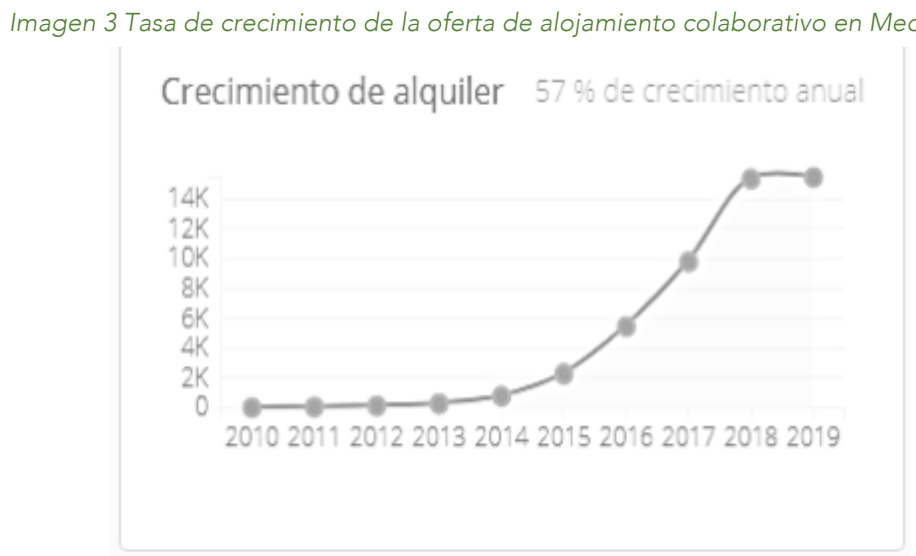

Fuente: Airbnb Data \& Analytics. (MarketMinder SM, 2019)

Airbnb es la plataforma con más fuerza en el mercado y la que tiene la mayoría de oferta, en Medellín cuenta con más de 1.700 apartamentos y habitaciones que representan el $50 \%$ de la oferta dentro de la ciudad de ahí la importancia y competencia que pueden llegar a generar pues desde el 2013 año en que llegó al país y comenzó su aplicación en la ciudad la ocupación hotelera ha ido disminuyendo considerablemente. (Sarmiento, 2019).

Con el fin de establecer los puntos de encuentro y diferencias entre los dos modelos, economía tradicional y economía colaborativa se aplican las técnicas encuesta y entrevista a la población seleccionada desde la metodología, los resultados reflejan la posición que tienen los empresarios, administradores y/o encargados de hoteles, hostales y corporaciones empresariales frente al creciente fenómeno.

Algunas de sus apreciaciones se muestran a continuación: 
Imagen 4 Resultados encuesta prestadores de servicios de alojamiento

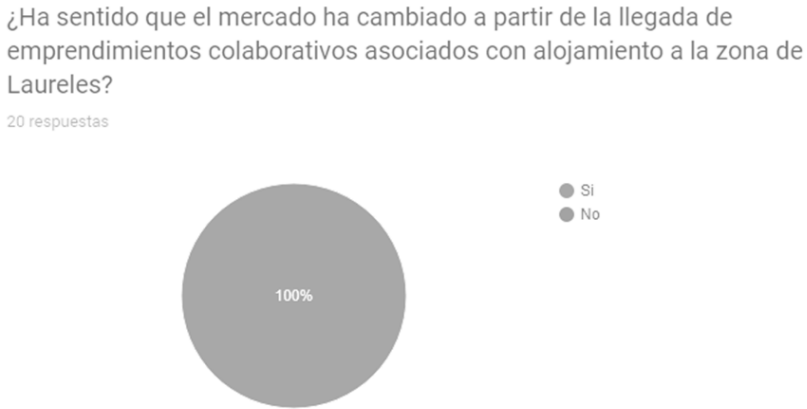

Fuente: Elaboración propia

Los 20 establecimientos manifiestan que el mercado ha cambiado por la popularización de los alojamientos colaborativos en la zona, esto indica que es inevitable que el mercado compuesto por oferta y demanda no se desestabilice de algún modo por la llegada de mayor oferta aun cuando esta se trate de servicios sustitutos. Por lo menos la forma de comercializarse y comunicarse con su público objetivo de viajeros potenciales cambia por la llegada de tecnologías de la información y comunicación, así como las plataformas de intermediación digital en servicios de turismo.

Para los alojamientos tradicionales no solo ha cambiado el entorno del mercado, el 94,7\% de los empresarios manifiestan que de la misma manera la dinámica interna de su negocio relacionada con talento humano, contratación de personal, estructura organizacional, normas y procedimientos, mercadeo interno y demás, han tenido que sufrir cambios y reestructuraciones así como la forma de relacionarse en el medio con proveedores, agentes reguladores y hasta competidores o empresas pertenecientes a la cadena de valor en turismo se modifica 
por la llegada de nuevos actores al mercado en este caso los emprendimientos de tipo colaborativo.

Los empresarios tradicionales, definen entre negativos y retadores los cambios a los cuales se han tenido que enfrentar por la llegada a su zona de economías colaborativas en alojamiento.

Como estrategias de integración de ambos modelos, los empresarios tradicionales proponen:

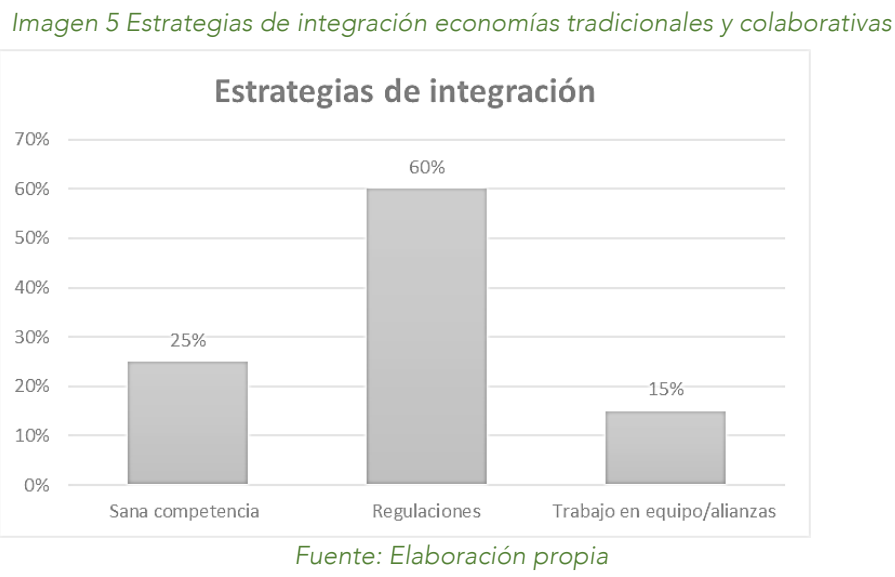

Por su parte en las entrevistas, los coordinadores de los gremios hoteleros de la zona manifiestan que los modelos empresariales tradicionales deben reestructurarse para hacer frente a los alojamientos colaborativos principalmente en la forma como comunican los servicios a los viajeros quienes son personas que no entienden de tecnicismos y demandan un lenguaje más común y amigable.

La investigación de mercado es clave a la hora de competir, los alojamientos deben entender la necesidad real de los consumidores y lo que hace que los elijan o no. 


\section{Discusiones}

La percepción que tienen los empresarios de los alojamientos tradicionales respecto a los cambios del mercado en general es negativa, esta se puede interpretar como una resistencia a los cambios

y de acuerdo con ELDE (2018), las causas más comunes que tienen las empresas y sus colaboradores para generar una reacción de resistencia al cambio están relacionadas con: incertidumbre, falta de información, percepción de amenazas, clima de baja confianza administrativa en este caso en la gestión pública y de regulación, resistencia a experimentar, poca flexibilidad organizativa, aumento de las responsabilidades laborales y temor a no poder aprender las nuevas destrezas requeridas.

Debe buscarse la manera de eliminar esas barreras identificando cuál o cuáles puntualmente se presentan para cada establecimiento de modo que en los empresarios y empleados se propicie un entorno de aprendizaje a las nuevas dinámicas del mercado asumiendo para este un rol positivo y participativo más que de reproche.

Internamente las organizaciones tradicionales han tenido que reestructurarse para hacer frente a la gran ola colaborativa que inundó la Comuna 11 de Medellín; en términos generales entre las áreas de mercadeo y servicios al huésped se define la brecha que separa a los tipos de alojamientos; sin mencionar el aspecto de formalización y legalidad presente en los tradicionales pero ausente en los alojamientos colaborativos debido al vacío legal que presenta el país 
y, que causa la mayor inconformidad y deterioro de la relación entre ambos.

La característica que identifican como valor agregado los alojamientos tradicionales es lo que paradójicamente los vuelve menos competitivos en el mercado actual debido a que las "comodidades" de un hotel u alojamiento tradicional pasaron a un segundo plano para demanda, ahora entre las prioridades de los viajeros se encuentra la economía y la relación favorable entre precio y servicios básicos (cama, baño y conectividad). Cabe aclarar que sigue existiendo demanda para los dos tipos de alojamiento.

De acuerdo con la información suministrada por la directora de la corporación hotelera, los empresarios tradicionales en lugar de realizar cambios al interior de sus establecimientos, procesos y actividades están optando por unirse a la informalidad y abrir negocios de tipo colaborativo, emprenden en esa modalidad dado que les implica menos responsabilidades y con su experiencia en el mercado posiblemente mayores ingresos.

En términos generales se puede evidenciar la manera como de acuerdo con la legislación empresarial y turística del país se carga de requerimientos a los prestadores de servicio de alojamiento tradicional aun cuando la demanda real y actual de los servicios no lo esté requiriendo ni valorando.

Desde las diferentes mesas y entornos en los que se habla del duro golpe que le ha dado a la hotelería tradicional la llegada de economías colaborativas la solución que se propone siempre está relacionada con el aspecto de legalidad y regulación, los empresarios identifican que si toda 
la oferta de alojamiento trabaja bajo las mismas condiciones en cuanto a impuestos, normatividad y plataformas, el sentimiento de que hacer las cosas bien no genera tan buenos resultados desaparecerá y las economías colaborativas podrían integrarse en la tarea de favorecer el desarrollo económico sostenible de los destinos.

Se requiere en todo caso que el estado en todos sus niveles brinde un acompañamiento a los alojamientos tradicionales para que estos logren implementar procesos en innovación, competitividad y promoción, así como desde el estado se concerté la base de impuestos y carga legal que regirá sobre las economías colaborativas de modo que se les permita participar en las rentas de la industria turística y aportar para su fortalecimiento.

Por su parte la ley general de turismo 1558 de 2012 en su artículo 16 parágrafo 1 define: "Para los efectos tributarios o fiscales de la presente ley, se considera que prestan los servicios de vivienda turística las personas naturales o jurídicas cuya actividad sea la de arrendar o subarrendar por periodos inferiores a 30 días con o sin servicios complementarios, bienes raíces de su propiedad o de terceros o realizar labores de intermediación entre arrendadores y arrendatarios para arrendar inmuebles en las condiciones antes señaladas. Se presume que quien aparezca arrendando en un mismo municipio o distrito más de cinco inmuebles de su propiedad o de terceros por periodos inferiores a 30 días es prestador turístico". (Congreso de Colombia, 2012).

Esto quiere decir que para la legislación y regulación vigente en el país se reconocen como prestadores de servicios turísticos aquellos 
empresarios en economías colaborativas que posean más de 5 propiedades en arriendo no permanente. En términos generales en el país la economía colaborativa es asumida como una alternativa de ingresos diferente a la principal ocupación del emprendedor, lo común es que las personas tengan en renta una segunda vivienda, no es común denominador que un mismo empresario del alojamiento colaborativo tenga más de 5 propiedades en el negocio, por lo tanto la distribución de "empresarios" gracias al fácil acceso al mercado es mucho mayor a la de un negocio formal donde se consolidan cadenas o grupos empresariales de un mismo dueño o socio. Con esto se quiere decir que la ruta de normalización y legalización de estos pequeños emprendimientos con menos de 5 propiedades no se lleva a cabo en concordancia con lo que la legislación vigente del país determina.

El sector público deberá controlar el crecimiento acelerado de la competencia colaborativa, para que desde oferta no se afecte la prestación de los servicios y la imagen del destino, esta meta es difícil de lograr dado que de acuerdo con una de las expertas entrevistadas los alojamientos colaborativos se mantienen escondidos tras la informalidad, el hecho de que no tengan un letrero en su fachada que los visibilice les hace más fácil su operación en la ilegalidad e incluso su proliferación, la informalidad contribuye a que para los entes de control sea difícil su detección y que cuando un alojamiento de estos sale a la luz es porque las denuncias y quejas contra la prestación de servicios y actividades irregulares han sido constantes generalmente por parte de los vecinos del sector. 
Para el logro de los objetivos sostenibles que en materia de turismo se plantee la ciudad y específicamente la zona de Laureles-Estadio, es necesaria la cohesión de todos los prestadores de servicios turísticos, un dialogo fluido y trabajo en equipo permitirá en la comuna 11 un crecimiento responsable de la actividad turística. El trabajo articulado es la base para alcanzar la competitividad, innovar y diversificar constantemente en la oferta para satisfacer las necesidades no solo de alojamiento si no de servicios generales para todos los turistas que llegan a la zona.

\section{Conclusiones}

Las economías colaborativas han existido desde el origen de los tiempos, el auge que se ha venido dando en la última década y que ha llevado a que en diferentes contextos se hable del tema tanto en transporte, turismo, finanzas, entre otras, se debe principalmente a la relación que se ha desarrollado entre emprendimientos colaborativos y aplicación de tecnologías digitales para el acercamiento de oferta con la demanda.

El estudio de los cambios en los modelos de negocio de alojamiento tradicional frente a la llegada de alojamientos colaborativos a la luz de la búsqueda del desarrollo económico y sostenible de los destinos, permite concluir en términos generales que los servicios alojamiento colaborativo ofrecidos en plataformas como Airbnb no se encuentran en las mismas condiciones de competencia en términos de seguridad, características del servicio y respaldo, 
Airbnb presenta su valor agregado y ventaja para competir con los alojamientos formales y tradicionales en función del precio, el servicio asociado a las experiencias que facilita para sus viajeros, al ambiente de familiaridad y la relación de cercanía que se establece entre el huésped y el anfitrión propiciada por la plataforma.

Aunque puede establecerse una diferencia clara entre los alojamientos tradicionales y los colaborativos, los prestadores de servicios de alojamiento tradicional manifiestan en diferentes contextos su inconformidad ante la presencia de emprendimientos de tipo colaborativo en el mercado y específicamente en la zona de LaurelesEstadio, dicha inconformidad no se trata de egoísmo o cierre en el mercado si no que está relacionada con las condiciones que el entorno legal le plantea o exige a los hoteles y hostales tradicionales, exigencias que no se tienen para los alojamientos colaborativos, esto ha llevado a que popularmente los alojamientos colaborativos sean conocidos como "informales" y a que esta informalidad propicie en el sector y en el destino en general un entorno de baja competitividad y pérdida de control y regulación de la actividad turística así como todo lo que deriva de ella: impactos turísticos, generación de empleo, ingresos económicos por turismo, estadísticas, crecimiento real del turismo en el territorio, etc.

En cuanto a la gestión pública la presencia de economías colaborativas no permite vislumbrar de manera real las estadísticas empresariales del sector, ingresos y consumo regular por parte de los turistas, esto a su vez no permite ver el crecimiento económico real del territorio. Por tanto, es fundamental que las autoridades ejerzan control y se formulen regulaciones sobre estas actividades. 
Los alojamientos colaborativos se encuentran en toda la ciudad porque lo para los turistas es atractivo poder alojarse en sectores cuentan con fácil acceso, transporte, cercanía a sitios de interés, oferta gastronómica y de servicios; para el caso del sector de LaurelesEstadio lo que ha representado una ventaja comparativa para los hoteles y hostales de la zona, se ha convertido también en el foco de atención para la competencia representada por apartamentos y casa de familia que quedan en la zona.

\section{Referencias}

Airbnb Inc. (21 de enero de 2019). Términos del servicio Airbnb. Recuperado el 31 de enero de 2019, de https://www.airbnb.es/terms?euid=ced9b32a-611e-9007-1dd802fefe039cab\&src=omni\%5B27259\%5D\&\#noneu

Alcaldía de Medellín. (diciembre de 2017). Plan Estratégico en el marco de la política pública de turismo de Medellín. Medellín, Antioquia, Colombia.

Alcaldía de Medellín. (septiembre de 2015). Plan de desarrollo local comuna 11 Laureles Estadio. Medellín. Obtenido de https://www.medellin.gov.co/irj/go/km/docs/pccdesign/SubportaldelCiudadano_2/PI andeDesarrollo_0_15/InformacinGeneral/Shared\%20Content/Documentos/comunas/ COMUNA11_LAURELES_ESTADIO.pdf

Alegre, J. (15 de diciembre de 2014). ¿Qué es la Economía Colaborativa? Obtenido de Economistas frente a la crisis: https://economistasfrentealacrisis.com/que-es-laeconomia-colaborativa/

All the rooms. (2018). All the rooms. Recuperado el enero de 2019, de https://www.alltherooms.com/

Bagó, A. C. (2012). Innovación en modelos socio-económicos. Introducción al consumo colaborativo. Obtenido de https://www.scribd.com/fullscreen/58880914?acces s_key=key-2fi003avv1spqak6f6pv

Banco Interamericano de Desarrollo, Fondo Multilateral de Inversiones. (2016). Economía colaborativa en América Latina. Madrid: IE Bussiness School.

Buenadicha, C., Cañigueral Bagó, A., \& De León, I. (junio de 2017). Retos y posibilidades de la economía colaborativa en América Latina y el Caribe.

Cañigueral, A. (2016). Hacia una economía colaborativa «responsable». oikomics, 2-10. Recuperado el 04 de 12 de 2019, de http://oikonomics.uoc.edu/divulgacio/oikonomics/_recursos/documents/06/03_Oikon omics_6_Canigueral_es_2016.pdf 
Colombia, C. d. (23 de 05 de 2017). Ley 1834 Fomento de la economía colaborativa Ley Naranja. Bogotá, Colombia. Recuperado el 31 de enero de 2019, de http://es.presidencia.gov.co/normativa/normativa/LEY\%201834\%20DEL\%2023\%20DE \%20MAYO\%20DE\%202017.pdf

Davis, A. M. (2008). Economía creativa como estrategia de desarrollo: una visión de los países en desarrollo. En A. C. Rei. Sao Paulo: Itaú cultural.

Diaz Armas, F. J.-R. (2014). Airbnb como nuevo modelo de negocio disruptivo en la empresa turística: un análisis de su potencial competitivo a partir de las opiniones de los usuarios. Recuperado el 1 de febrero de 2019, de https://www.researchgate.net/profile/Desiderio_Tano/publication/270394571_Airbnb _como_nuevo_modelo_de_negocio_disruptivo_en_la_empresa_turistica_un_analisis_d e_su_potencial_competitivo_a_partir_de_las_opiniones_de_los_usuarios/links/54d0a3 830cf20323c2181a

Encarnación, A. M. (2018). Revista de estudio de la administración local y autonómica. (I. n. España, Ed.) Recuperado el 04 de 12 de 2018, de http://revistasonline.inap.es/index.php?journal=REALA\&page=article\&op=view\&path $\% 5 B \% 5 D=10350 \&$ path\%5B\%5D=10928

Fenalco Antioquia. (diciembre de 2018). SITUR. Recuperado el 23 de enero de 2019, de http://situr.gov.co/estadisticas/statistics/\#!tabset_0=3

Ferrer, M. (2016). La normalización de la Economía Colaborativa.

Flórez, M. A., Fernández Ospina, J., Escalante Álzate, V., \& Puerta Correa, V. (2019). Informe de economías colaborativas. Medellín.

García, M. M., Viana Mesa, D., \& Yepes Valencia, D. (2019). Los riesgos de la economía compartida para la economía tradicional. Medellín, Colombia.

Gómez, J. P., \& Martínez Meza, R. (s.f.). El impacto de la economía colaborativa en la generación de estrategias de transformación empresarial en las MiPymes del departamento de Antioquia. Bello, Antioquia, Colombia.

Guillén Navarro, N. (2016). Acción pública y consumo colaborativo. Regulación de las viviendas de uso turístico en el contexto P2P. PASOS Revista de turismo y patrimonio cultural, 2, 3, 4, 5. Recuperado el 04 de 12 de 2018, de http://www.pasosonline.org/Publicados/14316/PS316_13.pdf

Gutiérrez, F. (2016). Confianza y cooperación: el corazón de la Economía Colaborativa en Medellín.

Hosteltur. (24 de 05 de 2019). Hoteleros de todo el mundo se unen contra Airbnb. 5591. Barcelona, Cataluña, España. Obtenido de https://www.hosteltur.com/128413_hoteleros-de-todo-el-mundo-se-unen-contraairbnb.html

MarketMinder SM. (2019). AIRDND. Recuperado el 31 de enero de 2019, de https://www.airdna.co/vacation-rental-data/app/co/default/medellin/overview

Medellín cómo vamos. (2016). Medellín cómo vamos. Obtenido de https://www.medellincomovamos.org/la-ciudad/

Ministerio de comercio, i. y. (julio de 2012). Lineamientos de política para el desarrollo del turismo comunitario en Colombia. Bogotá, Colombia. Obtenido de 
http://citur.linktic.com/upload/publications/documentos/84.Politica_de_Turismo_Com unitario.Lineamientos_de_politica.pdf

Ministerio de Comercio, Industria y Turismo. (1 de noviembre de 2018). Decreto 2063 de 1 de noviembre de 2018. Decreto 2063 de 1 de noviembre de 2018. Bogotá, Cundinamarca, Colombia.

Ministerio de Comercio, Industria y Turismo. (2019). CITUR - Centro de Información Turística. Obtenido de CITUR - Centro de Información Turística: http://www.citur.gov.co/estadisticas/ver/index/34\#menu

Muñoz, C.Y. (2017). Turismo colaborativo en Colombia ¿una realidad? Universidad tecnológica de Bolívar, Bolívar.

Peterson, R. A. (2003). "Consumer information search behavior and the Internet". Psychology and Marketing.

ProColombia. (s.f.). colombia.travel. Recuperado el 13 de mayo de 2019, de http://www.colombia.travel/es/a-donde-ir/andina/medellin

Ramírez, M. P. (2017). TURISMO 2.0: LAS ECONOMÍAS COLABORATIVAS INNOVAN EL HOSPEDAJE. Institución universitaria Salazar y Herrera, Medellín.

Reis Organización. (2008). Economía creativa como estrategia de desarrollo: una visión de los países en desarrollo. Sao Paulo: Itaú cultural.

Rifkin, J. (2000). La era del acceso La revolución de la nueva economía. Paidós.

Rojas, R. R. (02 de 09 de 2015). Aspectos laborales de la economía colaborativa: ¿Hacia un nuevo modelo de sostenibilidad laboral para el siglo XXI? Obtenido de Elderecho.com: https://elderecho.com/aspectos-laborales-de-la-economia-colaborativa-hacia-unnuevo-modelo-de-sostenibilidad-laboral-para-el-siglo-xxi

Ruiz, M. S., \& Maudes Gutiérrez, A. (2016). La regulación debe justificarse por la existencia de fallos de mercado como la información asimétrica o la existencia de externalidades.

Sánchez, C. B., \& Ruiz de Munain, J. L. (2016). La Economía Colaborativa y su capacidad para transformar el desarrollo en América Latina.

Sánchez, D. (2015). Economía colaborativa y de recursos compartidos.

Sarmiento, S. R. (22 de 03 de 2019). Hoteles y apps, una disputa en cifras. (E. Colombiano, Ed.) Obtenido de https://www.elcolombiano.com/negocios/economia/que-tantomercado-le-quita-airbnb-a-los-hoteles-en-medellin-

ME10414549?fbclid=IwAROVwFgGnNZsgGQILLjRWp0cs8kBnLfq4Or6PZKMtFaKZc

Sistema de Indicadores Turísticos medellín-Antioquia. (2018). Informalidad del sector turístico Medellín 2018. Medellín.

Solanas, F. (2008). Economía creativa como estrategia de desarrollo: una visión de los países en desarrollo. En O. A. Reis. Sao Paulo: Itaú cultural.

Stokes, K. C. (2014). Making Sense of the UK Collaborative Economy. Recuperado el 26 de febrero de 2019, de https://collaborativeeconomy.com/wp/wpcontent/uploads/2015/04/making_sense_of_the_uk_collaborative_economy_14.pdf

Tunguz, T. (2011). The New Market Places - Peer to Peer Collaborative Consumption. Obtenido de http://miter.mit.edu/articlenew-market-places-peer-peer-collaborativeconsumption/

Universidad Externado de Colombia. (21 de octubre de 2012). Recuperado el 31 de enero de 
2019, de Turismo y servicios de acogida: http://turismoyserviciosdeacogida.blogspot.com/2012/10/gremios-e-institucionesdel-turismo-en.html

Valor, C. (2014). Economía en Colaboración. Economistas sin fronteras Dosier № 12. Obtenido de http://www.ecosfron.org/wp-content/uploads/DOSSIERES-EsF-12Econom\%C3\%ADa-en-colaboraci\%C3\%B3n.pdf

Vice Ministerio de Turismo, dirección de análisis sectorial y promoción. (2008). Definiciones y actividades prestadores de servicios turísticos. Bogotá.

Z Libra. (3 de abril de 2015). Z Libra. Obtenido de https://zetasoftware.com/blog/ 